\title{
Reproductive health for refugees by refugees in Guinea II: sexually transmitted infections
}

\author{
Mark I Chen*1, Anna von Roenne ${ }^{2}$, Yaya Souare ${ }^{3}$, Franz von Roenne ${ }^{2}$, \\ Akaco Ekirapa ${ }^{1}$, Natasha Howard ${ }^{1}$ and Matthias Borchert ${ }^{1}$
}

\author{
Address: ${ }^{1}$ London School of Hygiene and Tropical Medicine, London, UK, ${ }^{2}$ Gesellschaft für Technische Zusammenarbeit, Eschborn, Germany and \\ ${ }^{3}$ Reproductive Health Group, Guéckédou, Guinea \\ Email: Mark I Chen* - mark_chen@pacific.net.sg; Anna von Roenne - anna.von.roenne@gmx.de; Yaya Souare - yayaswaray@yahoo.com; \\ Franz von Roenne - franz.roenne@gtz.de; Akaco Ekirapa - ekira_26@hotmail.com; Natasha Howard - Natasha.Howard@lshtm.ac.uk; \\ Matthias Borchert - Matthias.Borchert@lshtm.ac.uk \\ * Corresponding author
}

Published: 23 October 2008

Conflict and Health 2008, 2:14 doi:10.1/86/1752-1505-2-14
Received: 29 July 2008

Accepted: 23 October 2008

This article is available from: http://www.conflictandhealth.com/content/2/1/14

(c) 2008 Chen et al; licensee BioMed Central Ltd.

This is an Open Access article distributed under the terms of the Creative Commons Attribution License (http://creativecommons.org/licenses/by/2.0), which permits unrestricted use, distribution, and reproduction in any medium, provided the original work is properly cited.

\begin{abstract}
Background: Providing reproductive and sexual health services is an important and challenging aspect of caring for displaced populations, and preventive and curative sexual health services may play a role in reducing HIV transmission in complex emergencies. From 1995, the non-governmental "Reproductive Health Group" (RHG) worked amongst refugees displaced by conflicts in Sierra Leone and Liberia (19892004). RHG recruited refugee nurses and midwives to provide reproductive and sexual health services for refugees in the Forest Region of Guinea, and trained refugee women as lay health workers. A crosssectional survey was conducted in 1999 to assess sexual health needs, knowledge and practices among refugees, and the potential impact of RHG's work.

Methods: Trained interviewers administered a questionnaire on self-reported STI symptoms, and sexual health knowledge, attitudes and practices to 445 men and 444 women selected through multistage stratified cluster sampling. Chi-squared tests were used where appropriate. Multivariable logistic regression with robust standard errors (to adjust for the cluster sampling design) was used to assess if factors such as source of information about sexually transmitted infections (STIs) was associated with better knowledge.

Results: $30 \%$ of women and $24 \%$ of men reported at least one episode of genital discharge and/or genital ulceration within the past 12 months. Only $25 \%$ correctly named all key symptoms of STIs in both sexes. Inappropriate beliefs (e.g. that swallowing tablets before sex, avoiding public toilets, and/or washing their genitals after sex protected against STIs) were prevalent. Respondents citing RHG facilitators as their information source were more likely to respond correctly about STIs; RHG facilitators were more frequently cited than non-healthcare information sources in men who correctly named the key STI symptoms (odds ratio $(\mathrm{OR})=5.2,95 \%$ confidence interval $(\mathrm{Cl})$ 1.9-13.9), and in men and women who correctly identified effective STI protection methods $(\mathrm{OR}=2.9,95 \% \mathrm{Cl} I .5-5.8$ and $\mathrm{OR}=4.6,95 \% \mathrm{Cl}$ I.6-13.2 respectively).

Conclusion: Our study revealed a high prevalence of STI symptoms, and gaps in sexual health knowledge in this displaced population. Learning about STIs from RHG health facilitators was associated with better knowledge. RHG's model could be considered in other complex emergency settings.
\end{abstract}




\section{Background}

Displaced populations continue to need reproductive and sexual health services during armed conflicts, which can last for decades [1]. The provision of reproductive and sexual healthcare in populations affected by complex emergencies poses a unique challenge. Behavioural changes arising from large population movements, social disruption and the poverty and violence experienced by displaced persons, may increase incidence of sexually transmitted infections (STIs) and HIV [2,3]. Men may have opportunistic sex or visit sex workers [4]. Women may be raped, coerced to trade sex, or enter relationships to secure basic survival $[3,5]$. However, there is evidence that the impact of conflict on the sexual transmission of HIV is context specific [6-9], depending on factors such as the prevalence of STIs and HIV in the populations involved and the adequacy of relevant refugee health services [10]. Health programmes must thus adapt their approaches to provide prevention and treatment services specific to the setting [11].

There has been a lack of published epidemiological research dealing with the implementation of sexual and reproductive health interventions for displaced populations [2]. Here we report about a knowledge, attitude and practice survey among Sierra Leonean and Liberian refugees of reproductive age, residing in camps in Guinea, where the "Reproductive Health Group" (RHG) had provided reproductive health services to refugees for several years. RHG, a local non-governmental organisation, is of special interest because they recruited nurses and midwives from the refugee community itself, and seconded them to Guinean health facilities, while trained refugee lay women provided contraceptives and health education, and drama groups attempted to specifically reach males and adolescents. Details on RHG's activities and the setting where they were active are described in the companion paper [12] and elsewhere [13].

The survey was conducted in 1999 and had the following objectives:

- To assess sexual health needs, knowledge and practices among refugees, e.g. prevalence of reported STI symptoms, knowledge about symptoms and prevention of STIs, treatment seeking and protective behaviour adopted by those experiencing STI symptoms

- To assess the potential impact of RHG's work, in terms of increased STI knowledge and more appropriate STIrelated behaviour in RHG clients

Survey results on family planning aspects are reported in the companion paper [12].

\section{Methods}

Details on study population, sampling strategy, survey methodology, data entry and analysis are provided in the companion paper [12]. In brief, a cross-sectional survey was conducted in a representative multistage sample of 889 reproductive-age men and women refugees from 48 camps served by RHG. In addition to socio-demographic information, survey sections of relevance here include questions on self-reported STI symptoms, and STI-related knowledge and behaviour. Respondents who had some knowledge of STIs were asked to name, unprompted, STI symptoms in men and women, and to assess a list of measures for protecting themselves from STIs - this list included two accepted and effective methods, and three inappropriate but prevalent methods. They were also asked about their main information source (e.g. health workers, RHG facilitators, dramas, friends, family, or media). In addition, respondents who reported genital discharge and/or ulceration within the past 12 months were asked about their treatment-seeking and partner notification/protection measures.

Study outcomes were:

- correctly identifying genital discharge AND genital ulcers in men and women as STI symptoms (key symptoms validated in African settings for syndromic STI management) [14]

- correctly identifying two accepted methods as effective for protecting against STIs (staying with one faithful partner, or using condoms during sexual intercourse)

- NOT agreeing that three inappropriate methods for protecting against STIs were effective (swallowing a tablet before sexual intercourse, avoiding public toilets, or - for women - washing their genitals after sexual intercourse)

- adopting an appropriate combination of behaviours when having STI symptoms, namely notifying their partner/s about their STI symptoms (which would facilitate care-seeking by the partner/s), AND protecting the partner/s from potential acquisition of an STI (either by abstaining from sex, or by using a condom)

Prevalence of these outcomes was compared between groups citing different sources of STI information and associations tested between outcome variables and sociodemographic and behavioural covariates. Chi-squared tests were used where appropriate. Covariates significant at $\mathrm{p}<0.10$ were entered into a multivariable logistic regression model. Robust standard errors were used to account for cluster sampling. 
The study received ethical clearance from the Ministry of Public Health in Guinea and the London School of Hygiene \& Tropical Medicine in the UK.

\section{Results}

The response rate exceeded $95 \%$, and the final sample used was 889 (445 men and 444 women). Results on demographics are reported in the companion paper [12].

\section{STI knowledge}

Most respondents (90\% of men, $92 \%$ of women) had some knowledge of STIs (Table 1). 43\% of men and 58\% of women (Chi2-test, $\mathrm{p}<0.001$ ) cited RHG facilitators as their main source of STI information, while $18 \%$ of respondents cited healthcare workers and 7\% RHG drama groups. Men indicated non-healthcare sources more frequently than women $(22 \%$ vs. $10 \%$, p $<0.001 ; 18 \%$ vs. $9 \%$ named friends and family as their main source of STI information, $4 \%$ vs. $<1 \%$ radio programmes or school). Self-reported STI symptoms were common, with $30 \%$ of women and $24 \%$ of men $(p=0.02)$ reporting at least one episode of genital discharge and/or ulceration within the past 12 months.

Figure 1 presents the results on knowledge of STI symptoms, showing the five STI symptoms most frequently named by the 399 men and 410 women who had some knowledge of STIs. Both sexes were more familiar with STI symptoms in their own rather than the opposite sex. While around $75 \%$ of respondents recognised penile discharge as an STI symptom, only $52 \%$ of men recognised vaginal discharge as a possible STI symptom for women. Only $32 \%$ of men and $42 \%$ of women suggested genital ulcers as STI symptoms in the opposite sex. Failure to recognise genital ulcers as an STI symptom in the opposite sex meant that only a minority of those who had some knowledge of STIs could correctly name the two key STI symptoms of genital discharge and genital ulceration for both sexes $(24 \%$ of men and $26 \%$ of women, respectively).

Table 2 (see additional file 1) presents STI prevention findings in individuals with some knowledge of STIs. Most respondents recognised that staying with one faithful partner and using condoms were effective, and $86 \%$ of men and $89 \%$ of women agreed with both methods. However, almost two thirds also judged one or more inappropriate STI prevention beliefs (e.g. swallowing tablets before sex, avoiding public toilets, and/or washing their genitals after sex) to be effective; only $38 \%$ of men and $41 \%$ of women rejected all inappropriate suggestions.

\section{STI treatment-seeking behaviour}

Figure 2 presents the behaviours reported by individuals when experiencing genital discharge and/or ulceration. Men were more likely than women to seek care from health facilities or to purchase medicines. Women were more likely than men to visit a traditional healer. Men were also more likely than women to notify their partners or avoid sex when symptomatic. Condom use, to protect partners when symptomatic, was infrequently reported by either sex. Approximately $78 \%$ of men adopted the appro-

Table I: Source of STI knowledge and prevalence of self-reported STI symptoms

\begin{tabular}{|c|c|c|c|}
\hline & $\begin{array}{c}\text { Men, } \\
N=445\end{array}$ & $\begin{array}{l}\text { Women, } \\
\mathrm{N}=444\end{array}$ & \\
\hline Characteristic & $\%(n)$ & $\%(n)$ & $\begin{array}{c}\text { P-value } \\
\text { (Chi test) }\end{array}$ \\
\hline Ever heard of STls & $89.7 \%(399)$ & $92.3 \%(410)$ & 0.163 \\
\hline Most important source of information about STIs & & & $<0.001$ \\
\hline \multicolumn{4}{|l|}{ Healthcare and RHG sources } \\
\hline - health workers & $17.1 \%(76)$ & $18.2 \%(81)$ & \\
\hline - RHG drama groups & $7.2 \%(32)$ & $6.3 \%(28)$ & \\
\hline - RHG health facilitators & $43.4 \%(193)$ & $57.7 \%(256)$ & \\
\hline \multicolumn{4}{|l|}{ Non-healthcare sources } \\
\hline - friends and family & $18.2 \%(8 I)$ & $9.5 \%(42)$ & \\
\hline - radio & $2.7 \%(12)$ & $0.2 \%(1)$ & \\
\hline - school & $0.9 \%(4)$ & $0.2 \%(1)$ & \\
\hline - others & $0.2 \%(1)$ & $0.2 \%(1)$ & \\
\hline \multicolumn{4}{|l|}{ Had STI symptoms in the past 12 months } \\
\hline - had genital discharge & $21.8 \%(97)$ & $26.6 \%(118)$ & 0.096 \\
\hline - had a genital ulcer & $8.8 \%(39)$ & $12.4 \%(55)$ & 0.079 \\
\hline - had either genital discharge or a genital ulcer & $23.6 \%(105)$ & $30.4 \%(135)$ & 0.022 \\
\hline - had both genital discharge and a genital ulcer & $7 \%(31)$ & $8.6 \%(38)$ & 0.375 \\
\hline
\end{tabular}




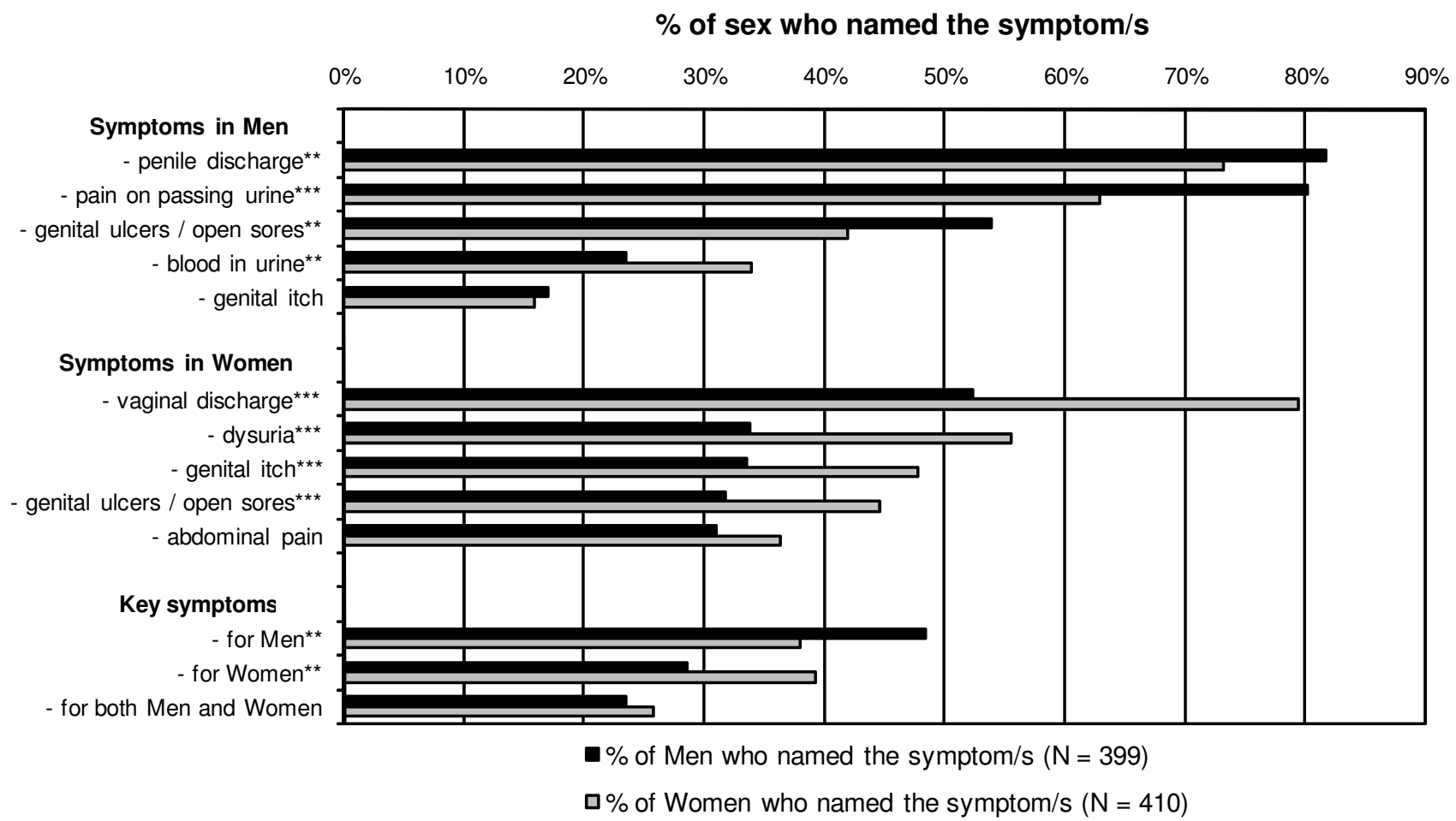

Figure I

Knowledge of STI symptoms in men and women, by sex of respondent. The 399 men and 410 women who had ever heard of STIs were asked to name, without prompting, STI symptoms in men and women. Results for the five STI symptoms most frequently named are presented; we also present the proportion that name a combination of key STI symptoms in men, in women, and in both men and women. Key symptoms were defined as penile discharge and genital ulcers/open sores in men, and vaginal discharge and genital ulcers/open sores in women. Items where the proportions differ significantly between genders are annotated (*** $p<0.001$, ** $p<0.01$, * $p<0.05)$.

priate combination of behaviours when perceiving STI symptoms, i.e. they reportedly informed their partner/s, and protected them from potential acquisition of the STI, mostly by stopping sex, less frequently by using a condom. This percentage was much lower in women (46\%).

\section{Outcome indicators by source of STI information}

Table 3 (see additional file 2) presents the prevalence of selected outcome indicators for men and women, grouped by STI information source. Among respondents who had some knowledge of STIs, correct knowledge about STI symptoms and prevention was significantly less frequent in those citing non-healthcare sources, while those citing RHG facilitators as their main information source were more likely to respond correctly. Among those with STI symptoms, respondents citing RHG facilitators as their main source of knowledge were more likely to adopt appropriate behaviours than those citing nonhealthcare sources, although this difference was not statistically significant. Several outcomes remained signifi- cantly associated with STI information source after adjusting for potential confounding in multivariable analyses. Both men and women who cited RHG facilitators were more likely to identify effective STI protection methods (adjusted odds ratio $(\mathrm{OR})=2.9,95 \%$ confidence interval (CI) 1.5-5.8 in men, and OR $=4.6,95 \%$ CI 1.613.2 in women) after adjusting for other factors significantly associated with this outcome (educational level and marital status in men, and educational level and age at first sexual intercourse in women). Respondents of both sexes who agreed with the two accepted methods of STI prevention were also marginally (but not significantly) more likely to identify key STI symptoms. Men citing RHG facilitators were significantly more likely to name the key STI symptoms (OR = 5.2, 95\% CI 1.9-13.9) when compared with those citing non-healthcare information sources. Women citing RHG facilitators were likewise more likely to name the key STI symptoms, but this association was not statistically significant (OR $=2.0,95 \%$ CI $0.9-4.6, \mathrm{p}=0.106)$, since levels of knowledge in 


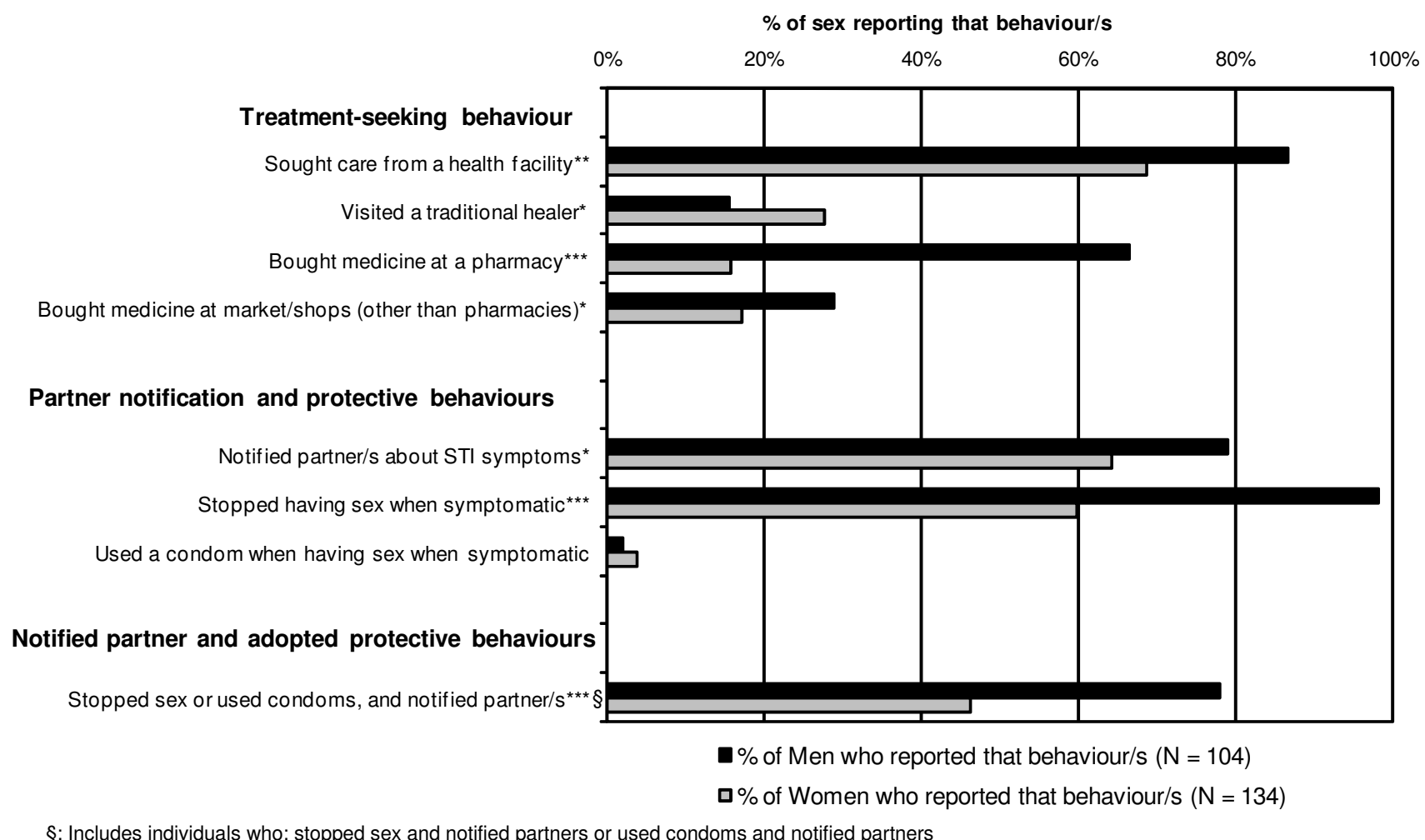

Figure 2

Treatment-seeking and partner notification/protection among symptomatic individuals, by sex of respondent. The 104 men and I 34 women who reported genital discharge and/or ulceration in the past 12 months were asked if they adopted any of these behaviours when having STI symptoms; note that each respondent could report more than one behaviour. We also present the proportion that adopted a combination of appropriate behaviours - either stopping sexual intercourse or using a condom, plus notifying their partner regarding their symptoms. Items where the proportions differ significantly between genders are annotated $\left(* * * p 0.001\right.$, ** $\left.\mathrm{p}<0.0 \mathrm{I},{ }^{*} \mathrm{p}<0.05\right)$.

women citing non-healthcare information sources was higher than for the men $(17.8 \%$ in women vs $8.2 \%$ in women, see Table 3 ). None of the sociodemographic or behavioural factors (age, religion, educational level, time in refugee camp, marital status and age at first sexual intercourse) were found to be associated with better knowledge about STI symptoms in either men or women.

\section{Discussion}

This survey, conducted under difficult conditions in a refugee population, highlights the necessity of good sexual health services for refugees. The majority of those displaced were sexually experienced; the prevalence of selfreported STI symptoms was high, in line with the high prevalence of lab-confirmed STIs in Rwandan refugees [15]. Similarly high estimates have been reported in reproductive-age women in non-emergency African settings [16].
Most respondents had heard of STIs, but many had only a superficial understanding. Less than 30\% identified the two key symptoms in both sexes. While genital discharge was generally known, genital ulcers (more important in facilitating HIV transmission [17]) were rarely named. Although most respondents correctly identified effective STI protection methods, the high prevalence of inappropriate beliefs echoed findings in other studies [4]. Some of these beliefs, such as avoiding public toilets, are clearly ineffective. Other beliefs, like swallowing a tablet before sex, could be effective in some circumstances (eg. antibiotics taken as prophylaxis against bacterial STIs [18]), but ineffective in others, and are therefore inappropriate; such a practice is also inappropriate because the misuse of drugs can cause adverse drug reactions and foster the emergence of resistance [19]. Moreover, believing in inappropriate methods may distract from accepted preventive measures, particularly if the inappropriate methods for 
protecting against STIs require less effort than the more effective ones (e.g. swallowing a tablet before sex or washing their genitals after sex versus condom use or faithfulness). Thus, community health education must not only inform about effective protection, but also dispel common but inappropriate beliefs about STI transmission.

Gender disparities were noted in treatment-seeking and partner notification. Underlying reasons why men more often purchased medications or accessed health facilities for STI symptoms while women favoured traditional healers may relate to the lack of financial resources available to women in a largely traditional society, but we did not explore this further in our study. Women were half as likely to notify their partners or adopt protective behaviours (mainly sexual abstinence) when symptomatic, suggesting they may have felt disempowered within sexual partnerships. Similar gender disparities reported in nonconflict African settings [20] further support the need for sexual health services and education to address the concerns of both men and women refugees. Gender disparities were similarly detected in the section of our survey dealing with knowledge and attitudes towards family planning [12].

Findings suggest that RHG's health education activities were effective. The survey, undertaken four years after RHG began, showed that RHG had gained sufficient credibility in this displaced population to be cited by most respondents as their main STI information source. Moreover, those who cited RHG facilitators were more likely to know key STI symptoms and effective STI prevention methods, and were less likely to maintain/cite inappropriate STI-related beliefs.

The study was subject to several limitations. First, no laboratory confirmation was possible for reported STI symptoms. However, syndromic STI identification has reasonable positive predictive value for STIs in high prevalence non-conflict African settings [14], and perceived STI is more relevant for health care seeking than actual STI. Second, reverse causality must be considered in crosssectional studies. One could argue that individuals did not become more knowledgeable through using RHG's services, but used RHG's services because they were more knowledgeable from the outset. Last, care needs to be taken when applying the findings of this study and the wider work concerning RHG's model for reproductive health to other conflict settings, as the services required in any complex emergency are determined by interactions between sexual health risks and needs among refugees, context of the conflict, and characteristics of the host country $[10,11]$.

\section{Conclusion}

Study findings reveal important gaps in sexual health knowledge, high burden of STI symptoms and insufficient access to STI services. The findings suggest the necessity and effectiveness of RHG's intervention model in this refugee population, and similar strategies could work in comparable contexts. In line with IAWG Field Manual on Refugee Reproductive Health guidelines, for refugees to participate in designing, maintaining and evaluating their own reproductive health services [21], the authors believe nurses, midwives and laywomen from the refugee community can provide essential reproductive health education and services to their fellow refugees. If properly supported, such programmes are more likely to be accepted and understood by the refugee community. This study contributes to the literature indicating such programmes are feasible and effective $[13,22]$. UNHCR and other agencies should consider supporting refugee health staff and community members in establishing community-based organisations to provide curative and preventive sexual and reproductive health services within the refugee population.

\section{Competing interests}

The authors declare that they have no competing interests.

\section{Authors' contributions}

All authors reviewed and approved of the manuscript. In addition, the specific roles were as follows. MIC analysed the data and drafted the manuscript AvR conceived the study, contributed to its design and to the interpretation of the data. YS was involved in the conception, design and acquisition of data for the study. FvR contributed to the design of the study, and the interpretation of the data. AE contributed to analysis and interpretation of the data $\mathrm{NH}$ contributed to analysis, interpretation of data, and critical revision of the manuscript $\mathrm{MB}$ designed the study, contributed to the acquisition, analysis and interpretation of data, and critically revised the manuscript.

\section{Additional material}

\section{Additional file 1}

Table 2 - Respondent's assessment of STI prevention methods (of those who had some knowledge of STIs). The file "RHG Oct 08 table 2.doc" contains Table 2 which is in landscape format.

Click here for file

[http://www.biomedcentral.com/content/supplementary/1752-

1505-2-14-S1.doc] 


\section{Additional file 2}

Table 3 - Outcome indicators by source of STI information. The file "RHG Oct 08 table 3.doc" contains Table 3 which is in landscape format. Click here for file

[http://www.biomedcentral.com/content/supplementary/17521505-2-14-S2.doc]

\section{Acknowledgements}

We wish to acknowledge the participation of the refugee communities, without whom this research would not have been possible. We would like to thank the local staff and workers of the Reproductive Health Group, and acknowledge the local authorities in Guinea, GTZ Guinea, and UNHCR for their support, and finally, GTZ for providing the necessary funding. We thank Philippe Mayaud from the London School of Hygiene for his insightful comments and suggestions during the editing of earlier drafts of this paper.

\section{References}

I. Whelan A, Blogg J: 'Halfway people': Refugee views of reproductive health services. Global Public Health 2007, 2:373-394.

2. Khaw AJ, Salama P, Burkholder B, Dondero T]: HIV risk and prevention in emergency-affected populations: a review. Disasters 2000, 24: $181-197$.

3. Krause SK, Jones RK, Purdin SJ: Programmatic Responses to Refugees' Reproductive Health Needs. Int Fam Plan Perspect 2000, 26:18I-187.

4. Holt BY, Effler P, Brady W, Friday J, Belay E, Parker K, Toole M: Planning STI/HIV prevention among refugees and mobile populations: situation assessment of Sudanese refugees. Disasters 2003, 27:I-I5.

5. Palmer $C A, Z$ wi $A B$ : Women, health and humanitarian aid in conflict. Disasters 1998, 22:236-249.

6. Salama P, Spiegel P, Talley L, Waldman R: Lessons learned from complex emergencies over past decade. Lancet 2004 364: $|80|-|8| 3$.

7. McGinn T, Purdin S: Editorial: Reproductive health and conflict: looking back and moving ahead. Disasters 2004, 28:235-238.

8. Spiegel PB, Bennedsen AR, Claass J, Bruns L, Patterson N, Yiweza D, Schilperoord M: Prevalence of HIV infection in conflictaffected and displaced people in seven sub-Saharan African countries: a systematic review. Lancet 2007, 369:2। 87-2195.

9. Strand RT, Fernandes Dias L, Bergstrom S, Andersson S: Unexpected low prevalence of HIV among fertile women in Luanda, Angola. Does war prevent the spread of HIV? Int J STD AIDS 2007, 18:467-47I.

10. Spiegel PB: HIVIAIDS among conflict-affected and displaced populations: dispelling myths and taking action. Disasters 2004, 28:322-339.

II. Mills EJ, Singh S, Nelson BD, Nachega JB: The impact of conflict on HIVIAIDS in sub-Saharan Africa. Int J STD AIDS 2006, I7:713-717.

12. Howard N, Kollie S, Souare Y, Roenne AV, Blankhart D, Newey C Chen M, Borchert M: Reproductive health services for refugees by refugees in Guinea I: family planning. Confl Health in press.

13. Roenne AV, Roenne FV, Kollie S, Swaray Y, Borchert M: Reproductive Health Services for Refugees by Refugees: An example from Guinea. Disasters in press.

14. Pickering JM, Whitworth JA, Hughes P, Kasse M, Morgan D, Mayanja $B$, Paal $L$ Van der, Mayaud $P$. Aetiology of sexually transmitted infections and response to syndromic treatment in southwest Uganda. Sex Transm Infect 2005, 81:488-493.

15. Mayaud P, Msuya W, Todd J, Kaatano G, West B, Begkoyian G, Grosskurth H, Mabey D: STD rapid assessment in Rwandan refugee camps in Tanzania. Genitourin Med 1997, 73:33-38.

16. Wilkinson D, Abdool Karim SS, Harrison A, Lurie M, Colvin M, Connolly C, Sturm AW: Unrecognized sexually transmitted infections in rural South African women: a hidden epidemic. Bull World Health Organ 1999, 77:22-28.
17. Gray RH, Wawer MJ, Brookmeyer R, Sewankambo NK, Serwadda D, Wabwire-Mangen F, Lutalo T, Li X, van Cott T, Quinn TC: Probability of HIV-I transmission per coital act in monogamous, heterosexual, HIV-I-discordant couples in Rakai, Uganda. Lancet 200I, 357:II49-III53.

18. Goh CL, Meija P, Sng EH, Rajan VS, Thirumoorthy T: Chemoprophylaxis and gonococcal infections in prostitutes. Int I Epidemiol 1984, 13:344-346.

19. Tapsall JW: What management is there for gonorrhea in the postquinolone era? Sex Transm Dis 2006, 33:8-10.

20. Voeten HA, O'Hara HB, Kusimba J, Otido JM, Ndinya-Achola JO, Bwayo Jl, Varkevisser CM, Habbema JD: Gender differences in health care-seeking behavior for sexually transmitted diseases: a population-based study in Nairobi, Kenya. Sex Transm Dis 2004, $31: 265-272$

21. UNHCR: Inter-agency Field Manual on RH services for refugees 1999

22. Nanayakkara A, Guy S: Reproductive health services for internally displaced people in Sri Lanka. Sexual Health Exchange 2003, 2:15-16.
Publish with BioMed Central and every scientist can read your work free of charge

"BioMed Central will be the most significant development for disseminating the results of biomedical research in our lifetime. "

Sir Paul Nurse, Cancer Research UK

Your research papers will be:

- available free of charge to the entire biomedical community

- peer reviewed and published immediately upon acceptance

- cited in PubMed and archived on PubMed Central

- yours - you keep the copyright 